\title{
Learning Processes and Academic Achievement among Secondary School Students in Barbados
}

\author{
Jason Marshall $^{1, *}$, Donna-Maria Maynard ${ }^{1} \&$ Rasheda Marshall $^{1}$ \\ ${ }^{1}$ School of Education, The University of the West Indies, Cave Hill Campus, Barbados \\ *Corresponding author: School of Education, The University of the West Indies, Cave Hill \\ Campus, Barbados. E-mail: jason.marshall@cavehill.uwi.edu
}

Received: May 1, 2015 Accepted: August 12, 2015 Published: August 26, 2015

doi:10.5296/ije.v7i3.7521 URL: http://dx.doi.org/10.5296/ije.v7i3.7521

\begin{abstract}
This study investigates the influence of learning processes on student achievement. One hundred and thirty-four students from eight secondary schools in Barbados were purposively selected and surveyed using the Inventory of Learning Processes (ILP; Schmeck, Ribich, \& Ramanaiah, 1977) subscales: fact retention, study methods, elaborative processing, and deep processing. The results indicate that the elaborative processing subscale was the only measure that was significantly related to student achievement in the sample. No significant differences emerged between high and low-achieving students in terms of the learning processes they employ. The findings suggest the importance of using higher-order learning strategies to facilitate academic success.
\end{abstract}

Keywords: academic achievement, deep processing, inventory of learning processes, learning styles, high-achieving, low-achieving 


\section{Introduction}

The learning processes that students engage in are vital to their academic success. Most of the research literature indicates a strong association between the use of deep processing, elaborative processing, and student achievement (Bhatti \& Bart, 2013; Carnicom \& Clump, 2004; Entwistle, 1991; Komarraju, Karau, Schmeck, \& Avdic, 2011; Schmeck, Ribich, \& Ramaniah, 1977). Despite such compelling findings, educators continue to place emphasis on traditional learning style measures as a means of understanding and facilitating student achievement (Schmeck, et al., 1977). Such measures highlight the sensory modalities (visual, auditory, and touch) as the main components that trigger students' learning and influence their achievement (Cassidy, 2004). As such, when most educators speak about learning styles they emphasise instructional preference models. For example, the VARK (visual, auditory, $\mathrm{read} /$ write, and kinaesthetic) learning style model (Fleming, 1987) is often referred to in student learning styles literature. With the emphasis on models of instructional preferences, less attention is given to information-processing learning style models that examine the higher-order learning processes of students (Bhatti \& Bart, 2013). This particular branch of learning styles highlights students' cognitive approaches to understanding and assimilating information.

A number of theoretical perspectives on learning styles indicate that the way students cognitively process information is a good gauge of how well they are likely to perform in school (Carnicom \& Clump, 2004; Entwistle, 1991; Komarraju, Karau, Schmeck, \& Avdic, 2011; Schmeck et al., 1977). These theoretical perspectives deemphasise the sensory modalities as measures of learning styles and instead focus on the depth of processing that students engage in as an important contributory factor to student achievement.

The seminal works of Schmeck et al. (1977) and other learning style theorists such as Entwistle (1991) and Kolb (1984) are testament to the importance of higher-order learning processes to student achievement. Each of these theorists emphasise the cognitive processes students engage when interacting with learning material. Entwistle (1991), for example, highlights the importance of understanding deep approaches to learning and contends that students who engage in deep and meaningful reflection on material are more likely to do well in school. This contrasts with surface processing where students tend to deemphasise elaboration and critical thinking and instead focus on rote memorisation as a means of retaining information.

Though Entwistle's work and measures of learning styles are well-documented, the work of Schmeck et al. (1977) provides a useful alternative to our understanding of learning styles. Using their Inventory of Learning Processes (ILP), these authors highlight the importance of student approaches to learning. The ILP is regarded as one of the most comprehensive measures of learning styles, based on the information processing framework of Craik and Lockhart (1975), the instrument was designed to assess the behavioural and conceptual processes that students engage in while learning new material (Schmeck et al., 1977).

The ILP comprises four subscales: methodical study, fact retention, elaborative processing, and deep processing. The methodical study subscale assesses a student's study habits. The 
fact retention subscale measures students' ability to correctly recall factual information and details, independent of deeper understanding or synthesis. The elaborative processing subscale assesses how students develop their own terminology for new information; generate concrete examples from their experience; personalize newly learnt information, and use visual imagery to encode ideas. Deep processing is the final subscale and measures the extent to which a student critically evaluates, conceptually organizes, and compares and contrasts new and existing information (Carnicom \& Clump, 2004; Schmeck et al., 1977).

A number of researchers, since the development of the ILP, have used it as a measure of learning styles (Cassidy, 2004; Clump, 2004; Duff, 1997), especially given its emphasis on deep processing. According to Schmeck (2011), deep processing involves focusing on the meaning of an idea rather than the idea itself. The literature has been consistent in showing that students who engage in deep processing are more likely to have high levels of academic achievement when compared to students who employ surface approaches to learning (Cassidy, 2004; Clump, 2005; Clump \& Sandoval, 2010; Duff, 1997; Entwistle, 1991; Schmeck et al., 1977). Those who support this view contend that the processes associated with elaboration on learning material enable students to develop a meaningful understanding of the information and increases the likelihood that it will be retained.

Findings from research studies support the claim that deeper levels of processing allow for effective learning (Gadzella \& Baloglu, 2003; Schmeck \& Grove, 1979). For example, Schmeck and Grove (1979) used the ILP to investigate the relationship between academic achievement and information processing habits relevant to learning. Their results indicate that the deep processing, fact retention and elaborative processing subscales of the ILP were significantly related to students' GPA. This suggests that students who do well in school tend to be deep processors who elaborate on what they are taught, while simultaneously retaining the details of the original information. Similarly, Gadzella and Baloglu (2003), found that high and low-achievers differ significantly on the type of learning styles they employ. Findings from their study revealed that high-achievers scored significantly higher than low-achievers on the elaborative processing and fact retention scales of the ILP. The findings indicate that these two techniques of processing information have a strong influence on academic success.

It is also important to note that obtaining high scores on each ILP subscale is not always indicative of the use of effective learning strategies. Some researchers contend that high scores on the study methods subscale are not always suggestive of high academic performance (Craik \&Tulvin, 1975; Schmeck, 1988). This point is supported by Craik and Tulvin (1975), who note that intent to learn is not always sufficient or in some cases necessary for learning to take place. Schmeck (1988) also endorses this view; he contends that scores on this scale are negatively related to grades, critical thinking ability, and cognitive development.

Some researchers argue that the inverse relationship between the study methods subscale and academic achievement may be reflective of the fact that this strategy is not as effective in assisting students in retaining material, particularly when compared to the higher-order 
thinking strategies such as deep processing and elaborative processing. This point is expressed by Craik and Lockhart (1972) who posited that retention is a function of depth, and various factors, such as the amount of attention devoted to a stimulus, its compatibility with the analyzing structures and the amount of time available to process the information, will influence the depth to which it is processed.

Unlike the varying findings for the study methods and fact retention subscales, research continues to be consistent in producing results which indicate that students who do well academically report high scores on the elaborative processing and deep processing subscales of the ILP (Duff, 1997; Schmeck et al., 1977). The consistency of this finding is not surprising given the fact that the focus of these methods of study are strongly related to critical thinking (Craik, 1975); a factor which many educational researchers have considered as essential in facilitating learning and fostering academic success (Duff, 1997; Grove, 1979).

Although adopting particular study strategies may prove useful, various learning strategies are employed by different types of students (Seaton, Marsh, \& Graven, 2010). This viewpoint is consistent with the research findings of Schmeck and Grove (1979), which indicate that there are significant differences in the information processing habits between high and low-achieving college students. Their results show that high-achieving students are more successful at processing information in-depth, organizing it and fitting it into a personal framework. On the other hand, low-achieving students tend to use conventional study methods instead of in-depth processing. It is important to note that some researchers have found that this is also a strategy that has been embraced by high-achieving students (Richardson \& Fergus, 1993; Schmeck \& Grove, 1979). Richardson and Fergus (1993), for example, note that some high-achieving students who work in an organised manner would use any needed approach to achieve good grades. This, they argue, includes the use of conventional as well as higher-order thinking strategies.

Research findings within the Caribbean have demonstrated that both deep processing and elaborative processing are essential to student attainment (Richardson \& Cato, 1999; Richardson \& Fergus, 1993). For example, a study conducted among a sample of Caribbean adolescents revealed that deep processing and elaborative processing were the preferred learning strategies among this sample of students (Richardson \& Cato, 1999). Similarly, Richardson and Fergus (1993) evaluated measures on the ILP in relation to ability grouping and found that students of the higher-ability group received significantly higher scores on the deep processing subscale when compared to their counterparts in the lower ability group. Based on these findings the researchers concluded that deep processing is associated with better academic performance, particularly because it is connected with good organisation of information, main ideas, supporting details, and meaningful associations (Richardson \& Fergus, 1993).

\section{The Present Study}

The findings from the previous research studies provide sufficient evidence that indicates the 
need for further research using ILP measures. The lack of research on student learning processes and their relationships with achievement among students at the secondary level suggests that research is warranted in this area. In addition, the emphasis of educators on preferred instructional learning style models (such as VARK, Fleming, 1987) as the primary model for understanding student-learning styles, points to the need for research that examines information-processing models of learning styles and the implications they have for student achievement. Moreover, the majority of research work that has examined student-learning processes has been conducted on college samples; few studies have examined student-learning processes at the secondary level. The present study was conceptualized with the aim of filling these gaps in the literature. More specifically, it was designed to investigate the relationship between the learning processes that secondary students employ and their academic performance. The study also sought to explore whether high and low-achieving students differ in the type of learning processing strategies they use. As such, this study was guided by the following research questions:

1) Are there any significant relationships between the ILP subscales and academic achievement among a sample of secondary school students in Barbados?

2) Are there any significant differences between high and low-achieving Barbadian secondary school students in relation to the learning processes that they employ?

\section{Method}

\subsection{Participants}

The sample in this study comprised 134 fourth and fifth form secondary school students from Barbados, aged 14-16. The mean age of the sample was 15.4 years. Of this number, 66 were classified as high-achieving students, while 68 were classified as low-achieving students. This classification was based on their Caribbean Secondary Examination Certificate (CSEC) General Proficiency English Language Examination results. These students were purposively selected from eight secondary schools. There were 87 females and 47 males who took part in the study.

\subsection{Procedures}

After obtaining permission from the Ministry of Education in Barbados to conduct the study, the principals of eight secondary schools were contacted and consented to the study being conducted at their respective institutions. Each principal was informed about the nature and purpose of the research. Students were selected using a non-probability purposive sampling technique, as they were required to be preparing to sit the English Language Caribbean Examinations Council (CXC), Caribbean Secondary Examination Certificate (CSEC). In an effort to locate students who met this criterion, the researcher was assisted by teachers or counsellors at each school to identify those students who were preparing to sit the Examination. Prior to the administration of the instrument, students were informed of the nature and purpose of the study and their assent to participate in the study was sought. They 
were also informed that they were free to withdraw from the study at any time without penalty.

\subsection{Measures}

Inventory of Learning Processes: The Inventory for Learning Processes was developed by Schmeck, Ribich, and Ramanaiah (1977) to assess the different types of processing that students engage in when dealing with information. The inventory has a total of 62 items encompassed in four subscales that measure different aspects of students' learning styles. The fact retention subscale has 7 items that focus on the student's tendency to memorise facts and details (Clump \& Sandoval, 2010). The study methods subscale has 23 items that assesses study habits of completing all assignments, attending classes, and putting great time and effort into studying (Marshall, 2014; Schmeck et al., 1977). The elaborative processing subscale has 14 items that measure how students personally encode and connect information (Clump \& Sandoval, 2010). The final subscale, deep processing, has 18 items designed to measure students' use of higher-order thinking (such as analysis and evaluation) strategies to retain information.

For each of the subscales on the ILP, the items are scored in a true or false response format. A score of one is given to those responses that indicated the statements were true and a score of zero is given to those responses that indicated that the statements were false. The instrument was scored by totalling the responses for each subscale.

The subscales of the ILP have strong psychometric properties. Schmeck et al. (1977) reported the following Cronbach alphas for deep processing $(\alpha=.82)$; elaborative processing; ( $\alpha$ $=.67)$; study methods $(\alpha=.74)$ and fact retention $(\alpha=.58)$. In Barbados, Hall (2013) reported Cronbach alphas for each subscale ranging from .72 to .83 (Deep processing - $\alpha=.83$; elaborative processing $-\alpha=.79$; study methods $-\alpha=.80$; and, fact retention $-\alpha=.72$ ).

\subsection{Academic Achievement}

Students' academic achievement was measured by using the grades they obtained after they completed the CXC CSEC General Proficiency English Language Examination. This examination assesses student proficiencies in important areas of English Language such as grammar, punctuation, and expository writing. Students enrolled in secondary schools who are in fourth and fifth form are required to write this examination.

Lower grades on CSEC examinations are indicative of higher academic performance, for example, Grades I, II, and III descend from excellent to satisfactory performance in any given subject area, whereas grades IV, V, VI are indicative of poor academic performance (CXC, 2015). However, for the purpose of this study, the marks were reverse scored so that a positive correlation would indicate a positive relationship between ILP scores and academic achievement.

Students were classified as either high or low-achieving based on their performance on the English Language examination. Students who received CSEC Grades I and II (Grades 6 and 5 respectively when reverse scored) were considered as high-achievers. By contrast, students 
who received CSEC Grades III and above (Grades of 3 and below when reverse scored) were considered as low-achievers. Based on the classification employed, 66 students were in the high-achieving group and 68 in the low-achieving group.

\section{Results}

To investigate whether there was a relationship between the ILP subscales and academic achievement Spearman's Rho was used. The results revealed that elaborative processing emerged as the only variable that was significantly related to student achievement, $\mathrm{n}=134 ; \mathrm{r}$ $=.234 ; \mathrm{p}<.05$ (See Table 1 below).

Table 1. Correlation Matrix for ILP Scales and Academic Achievement

\begin{tabular}{lccccc}
\hline & $\begin{array}{l}\text { Fact } \\
\text { retention }\end{array}$ & $\begin{array}{l}\text { Study } \\
\text { Methods }\end{array}$ & $\begin{array}{c}\text { Elaborative } \\
\text { processing }\end{array}$ & $\begin{array}{c}\text { Deep } \\
\text { Processing }\end{array}$ & $\begin{array}{c}\text { Academic } \\
\text { Achievement }\end{array}$ \\
\hline Fact retention & - & & & & \\
Study methods & .129 & - & & & \\
Elaborative processing & .053 & $.298^{* *}$ & - & & \\
Deep processing & $.276^{* *}$ & $.322^{* *}$ & $.400^{* *}$ & - & \\
Academic Achievement & -.037 & -.108 & $.234 * *$ & .045 & - \\
\hline
\end{tabular}

Independent samples t-tests were run to determine if there were any significant differences in the learning style approaches of high and low-achieving students. The results indicated that there were no significant differences between high and low-achieving students on any of the ILP measures. These results are displayed below in Table 2.

Table 2. Comparisons of High and Low-Achieving Students on ILP Subscales Using Independent Samples T-Tests

\begin{tabular}{|c|c|c|c|c|c|c|c|c|}
\hline \multirow[t]{2}{*}{$\begin{array}{l}\text { ILP } \\
\text { Subscales }\end{array}$} & \multicolumn{2}{|r|}{$\begin{array}{l}\text { High-Achieving } \\
\text { students }\end{array}$} & \multicolumn{4}{|c|}{$\begin{array}{c}\text { Low-Achieving } \\
\text { Students }\end{array}$} & & \\
\hline & $\mathrm{N}$ & M & $\mathrm{SD}$ & $\mathrm{N}$ & M & $\mathrm{SD}$ & $\mathrm{t}$ & $\mathrm{p}$ \\
\hline Fact Retention & 66 & 4.48 & 1.40 & 68 & 4.58 & 1.24 & -.429 & .67 \\
\hline Study Methods & 66 & 10.96 & 3.04 & 68 & 12.04 & 3.50 & -1.90 & .06 \\
\hline Elaborative Processing & 66 & 8.91 & 2.86 & 68 & 8.14 & 2.23 & 1.72 & .09 \\
\hline Deep Processing & 66 & 10.49 & 3.30 & 68 & 10. 20 & 3.09 & .53 & .60 \\
\hline
\end{tabular}

Note. $\mathrm{N}=$ Number of Students; $\mathrm{M}=$ Means; $\mathrm{SD}=$ Standard Deviations

\section{Discussion}

The primary aim of this study was to examine the relationship between the learning processes 
that students employ (as assessed by the ILP) and their academic achievement. The study also aimed to ascertain whether any significant differences would emerge between high and lowachieving students in relation to these learning processes. The results indicated that elaborative processing was the only variable that significantly related to student achievement. In contrast, there were no significant differences between high and low-achieving students on any of the ILP subscales.

The significant relationship that emerged between elaborative processing and academic achievement is consistent with extant literature (Bhatti \& Bart, 2013; Carnicom \& Clump, 2004; Entwistle, 1991; Komarraju, Karau, Schmeck, \& Avdic, 2011; Schmeck, et al., 1977; Seaton, Marsh, \& Graven, 2010). This finding is not surprising given that this subscale of the ILP taps into whether students personalize and elaborate on information that they are exposed to. Students who employ this method are more likely to retain information because they make meaningful associations between new information and pre-existing knowledge and utilize strategies such as visual encoding and personalization of information, which may assist in solidifying their memory of the concept(s) or material(s) (Clump, 2005; Clump \& Sandoval, 2010; Schmeck et al., 1977).

The non-significant relationship between deep processing and academic achievement found in this research is contrary to previous studies on learning styles (Clump, 2005; Duff, 1997; Entwistle, 1991; Schmeck et al., 1977). A probable explanation for this discrepancy in the research findings may be that the measure of academic achievement in this study - English Language performance - may not have required students to utilize deep processing. Moreover, elaborative processing may have sufficed as an approach to answering questions on the examination.

No significant differences emerged between high and low-achieving students on any of the learning style measures; this is inconsistent with previous literature (Duff, 1997; Richardson \& Cato, 1999; Richardson \& Fergus, 1999). For example, Gadzella and Balgolu (2003) found that high-achievers reported significantly higher scores than low-achievers on each of the learning style measures. As such, the finding of this present study is somewhat surprising as most researchers, like Gadzella and Balgolu, have found that students who are regarded as high- achievers tend to utilize deeper approaches to learning and in some cases they may adopt any approach that they see fit to help them retain information (Cassidy, 2004; Clump, 2005; Craik \& Lockhart, 1975; Entwistle, 1991; Duff, 1997; Richardson \& Cato, 1999; Richardson \& Fergus, 1993; Schmeck et al., 1977). This contrasts with the methods that are utilized by low-achievers who emphasize traditional study methods and may use one particular approach even if the learning situation demands a variety of approaches or a different approach.

The inconsistency in results between the current study and previous studies may be due to different sample types. More specifically, most of the research conducted using the ILP as a measure used students at the tertiary level, these students may have developed distinctive learning style approaches. In contrast, this study utilized students from the secondary level who may not have developed preferred learning style patterns as yet. 
In addition, due to the fact that the sample was drawn from a homogenous cohort of secondary school students in Barbados, the result may be indicative of the fact that these students are exposed to similar teaching strategies that emphasize similar methods of retaining information. Moreover, at the secondary level rote memorization may be emphasised and teachers may 'teach to the test' (Gallaghe, 2010). As a result, students may rely heavily on the memorisation of facts and important details and equate this practice with learning. In this study the high scores on the fact retention scale provide some evidence of this practice among the sample of students. However, it should be noted that scores on the fact retention subscale did not significantly correlate with academic achievement, which was the case with elaborative processing. What this demonstrates is the importance of encouraging students to engage their higher-order thinking skills when they are learning information. This is not only likely to boost their academic achievement, but will assist them in making meaningful connections with pre-existing knowledge, which in turn will concretize the 'new knowledge' that they are exposed to in school (Clump, 2005; Clump \& Sandoval, 2010; Schmeck et al., 1977). This will also set the foundation for them to be able to transfer their learning from inside the classroom to the 'real world'. This is extremely important as a comprehensive understanding of the English language is critical for success beyond school.

While no significant differences emerged between high and low-achievers in relation to their learning processes, it should be noted that the literature has consistently shown that high-achieving students are more likely to utilise deeper levels of processing than low-achieving students (Gadzella \& Baloglu, 2003). This suggests that high-achieving students utilise effective higher-order strategies to help them retain information; however, not all students may have this ability. This indicates that educators must not assume that all students know how to learn. In fact, in terms of instructional design and delivery, some components should be included that make students aware of the most effective strategies to help them to retain and understand the content that is being delivered.

Although the findings of this study have a number of implications in terms of teaching practice, these findings should be interpreted within the context of the research. The sample size for this research was relatively small, and as such, the findings may not be applicable to students outside of the Caribbean. It is recommended that future research be conducted on a larger sample of students within the region and beyond.

Moreover this study only utilised English Language as a measure of academic achievement, while this is a useful measure, it may not have given a comprehensive picture of the overall academic achievement of students who participated in this study. Therefore, future research should aim to include a greater variety of measures of academic achievement so as to provide a holistic picture of student attainment.

\section{Conclusion}

This study indicated that elaborative processing is significantly related to student achievement. This finding suggests that it is important for teachers and other educational 
stakeholders to encourage students to utilise learning strategies such as personalisation of information and visual encoding to help them retain information (Duff, 1977; Schmeck, et al., 1977). Contrary to previous research (Gadzella \& Balgolu, 2003) the results of this study showed that there are no significant differences between high and low-achieving students on any of the ILP measures. Given that most research which utilises the ILP as a measure of learning styles is conducted among students at the tertiary level, the discrepancies in results point to the need for additional research using the ILP with secondary school students.

\section{References}

Bhatti, R., \& Bart, W. M. (2013). On the effect of learning style on scholastic achievement. Current Issues in Education, 16(2), 1-6.

Carnicom, S., \& Clump, M. (2004). Assessing the learning style differences between honors students and non-honors students. Journal of the National Collegiate Honors Council, $138,36-44$.

Cassidy, S. (2004). Learning styles: An overview of theories, models, and measures. Educational Psychology, 24(4), 419-445. http://dx.doi.org/10.1080/0144341042000228834

Clump, M. (2005). Changes in students' learning processes following instruction on the topic. Journal of Instructional Psychology, 32(4), 293-297. http://dx.doi.org/10.1080/0144341042000228834

Craik, F., \& Lockhart, R. (1972). Levels of processing: A framework for memory research. Journal of Experimental Psychology, 11, 671-684. http://dx.doi.org/10.1016/s0022-5371(72)80001-x

Craik, F., \& Tulvin, E. (1975). Depth of processing and the retention of words in episodic memory research. Journal of Experimental Psychology: General, 104(3), 268-294. http://dx.doi.org/10.1037/0096-3445.104.3.268

CXC (2015) Retrieved from https://www.cxc.org/?q=examinations/understanding-our-exams/cxc-grade-system

Duff, A. (1997). Validating the learning styles questionnaire and the inventory of learning processes in accounting: A research note. Accounting Education, 6(3), 263-272. http://dx.doi.org/10.1080/096392897331497

Entwistle, J. (1991). Approaches to learning and perceptions of the learning environment. Higher Education, 22, 201-204.http://dx.doi.org/10.1007/BF00132287

Gadzella, B., \& Baloglu, M. (2003). High and low-achieving education students on processing, retaining and retrieval of information. Journal of Instructional Psychology, 30(2), 99-103.

Gallaghe, K. (2010). Why I will not teach to the test. Retrieved from 
http://216.78.200.159/RandD/Education\%20Week/Why\%20I\%20Will\%20Not\%20Teach $\% 20$ to $\% 20$ the $\% 20$ Test $\% 20-\% 20$ Gallagher.pdf

Hall, M. (2013). Selected psychosocial variables and performance on the BSSEE as predictors of academic outcomes (Unpublished doctoral dissertation). The University of the West Indies, Cave Hill Campus, Barbados.

Kolb, D. (1984). Experiential learning: Experience the source of learning and development. New Jersey, NJ: Prentice Hall Inc.

Komarraju, M., Karau, S., Schmeck, R., \& Avdic, A. (2011). The big five personality traits, learning styles and academic achievement. Personality and Individual Differences, 51(4), 472-478. http://dx.doi.org/10.1016/j.paid.2011.04.019

Marshall, J. (2014). An investigation into specified psychosocial variables and academic achievement among a sample of secondary school students in Barbados (Unpublished doctoral dissertation). The University of the West Indies, Cave Hill Campus, Barbados.

Richardson, A., \& Cato, B. (1999). Learning style, academic locus of control and creativity: A study of adolescent students in high schools in St. Vincent and the Grenadines. In Richardson, A. (Ed.), Caribbean Adolescents and Youth: Contemporary Issues in Personality Development and Behaviour (pp. 69-83). New York: Caribbean Diaspora Press.

Richardson, A., \& Fergus, E. (1993). Learning style and ability grouping in the high school system: Some Caribbean findings. Educational Research, 35(1), 69-76. http://dx.doi.org/10.1080/0013188930350104

Schmeck, R. (1988). Perspectives on individual differences: Learning strategies and styles of learning. New York, NY: Plenium Press. Retrieved from http://dx.doi.org/10.1007/978-1-4899-2118-5

Schmeck, R. R., \& Grove, E. (1979). Academic achievement and individual differences in learning processes. Applied Psychological Measurement, 3(1), 43-49. http://dx.doi.org/10.1177/014662167900300106

Schmeck, R., Ribich, D., \& Ramanaiah, N. (1977). Development of a self-report inventory for assessing individual differences in learning processes. Applied Psychological Measurement, 1(3), 413-431. http://dx.doi.org/10.1177/014662167700100310

\section{Copyright Disclaimer}

Copyright for this article is retained by the author(s), with first publication rights granted to the journal.

This is an open-access article distributed under the terms and conditions of the Creative Commons Attribution license (http://creativecommons.org/licenses/by/3.0/). 